\title{
Exploring how design-driven foresight can support strategic thinking in relation to sustainability and circular policy making
}

\author{
Rike Neuhoffa*, Luca Simeone ${ }^{b}$, Lea Holst Laursenc
}

\author{
a Aalborg University \\ b Aalborg University \\ 'Aalborg University \\ *Corresponding author email: rne@create.aau.dk
}

\begin{abstract}
:
Urgent and consequential issues related to climate change are driving forth the question of how to equip individuals with the competencies required to address sustainability issues. Strategic thinking is recognized as a key competency for developing plans and policy interventions that redirect social-ecological systems from unsustainable linear trajectories towards sustainable circular futures. Yet, the question of how strategic thinking capabilities can be cultivated, taught, or supported remains underexplored. In this study strategic thinking is associated with four central activities: vision thinking, divergent thought processing, reflection and systems thinking. The central aim of this paper is to explore how design-driven foresight, i.e. those approaches that combine design and foresight methods and tools, can support strategic thinking across these four activities and in relation to sustainability and circular policy making. This paper draws on two design experiments conducted with Service Design Master students at a Danish University.
\end{abstract}

Keywords: design-driven foresight, strategic thinking, sustainability, circular policy making

\section{Introduction}

Growing public awareness and concerns over environmental issues are driving forth the question of how to equip individuals and society with the competencies required to address sustainability issues (Wiek et al., 2011; Hale et al., 2015; Goldman et al., 2015). Strategic thinking, i.e. "the ability to collectively design and implement interventions, transitions, and transformative governance strategies" (Wiek et al. 2011, p. 210), is recognized as an invaluable key competency for developing plans on how to redirect social-ecological systems from unsustainable trajectories towards sustainable futures (Baumgartner \& Korhonen, 2010; Hale et al., 2015; Warren et al., 2014; Wiek et 
al., 2011). However, even in the business realm where most research about strategic thinking is rooted, the question of how strategic thinking capabilities can be developed, taught or supported remains underexplored (Grunwald, 2004; Goldman et al., 2015). This gap is fuelled by a muddled strategy lexicon that includes many, often somewhat overlapping, broad, and ill-defined strategyrelated terms, definitions and conceptualisations, and which sometimes leads to confusion rather than clarity (Goldman et al., 2015; Liedtka, 1998). This paper does not aim to tap into this specific gap, as other scholars have already provided in-depth reviews and nuanced perspectives on those existing conceptualisations around strategy (e.g. Simeone, 2020). Neither we want to introduce yet a new conceptualisation of strategic thinking but leverage existing research as a guardrail. Our aim with this paper is to take a design perspective and explore whether design-driven foresight, i.e. those approaches that combine design and foresight methods and tools, can support strategic thinking across its associated activities and in relation to circular policy making.

In the past, scholars have made valuable contributions about how design (Balkenende et al., 2017; Bofylatos et al., 2012; Giraldo Nohra et al., 2020; Lewis et al., 2017) as well as foresight (Destatte, 2010; Héry \& Malenfer, 2020; Wiener et al., 2020) can support sustainability and circular policy making. Furthermore, academic literature has described cases and frameworks in which methods from design and foresight were combined (Candy \& Kornet, 2019; Evans, 2010; Gordon et al., 2019). However, not much research has specifically examined how such a combination can fuel strategic thinking, in particular not in relation to sustainability and circular policy making.

\section{Literature Review}

\subsection{Conceptualising strategic thinking in relation to sustainability and circular policy making}

Strategic thinking, to date, has predominantly been addressed in an organisational context to drive competitive advantages (Bonn, 2005). Yet, driven by the urgent and consequential issues related to climate change, an emerging academic field has led to strategic thinking gaining traction in the context of sustainability (Wiek et al., 2011). In this realm, strategic thinking is recognized as a key competency to develop plans on how to redirect social-ecological systems from unsustainable trajectories towards sustainable futures (Baumgartner \& Korhonen, 2010; Hale et al., 2015; Warren et al., 2014; Wiek et al., 2011). Strategic thinking is recognized as an individual activity (Casey \& Goldman, 2010; Liedtka, 1998; Mintzberg, 1994), but as individuals think strategically in teams they improve their collective ability to "design and implement interventions, transitions, and transformative governance strategies towards sustainability" (Wiek et al. 2011, p. 210).

Though strategic thinking is seen as invaluable to drive environmental sustainability, it remains underexplored how it can be nurtured (Grunwald, 2004). Even the business environment offers sparse insights on effective approaches to do so (Bonn, 2005; Casey \& Goldman, 2010; Goldman et al., 2015), though this realm has long seen strategic thinking and the need to support the development of strategic thinking abilities of individuals as critical (Bonn, 2005; Casey \& Goldman, 2010; Goldman et al., 2015). What is commonly acknowledged is that strategic thinking is a dynamic, iterative, experiential, and interactive process (Casey \& Goldman, 2010; Mintzberg, 1994) and that for its development in the context of sustainability new problem- and solution-oriented approaches, and action-guided, social and reflective learning processes are important requirements (Grunwald, 
2004). However, the particular components of these learning processes and how to support them are underexplored (Casey \& Goldman, 2010).

One possible way to find out how strategic thinking can be supported is to conceptualise the latter according to its associated activities and to examine how design-driven foresight can fuel them. Srivastava \& D'Souza (2021) recently conducted a close review of prior research on this topic and synthesised a conceptualisation of strategic thinking composed of the following activities: divergent thought processing, reflection, and systems thinking. Though various other authors highlight 'vision thinking' in their conceptualisations (Bonn, 2005; Liedtka, 1998; Mintzberg, 1994; Wiek et al., 2011), Srivastava \& D'Souza (2021) intentionally left out this particular activity. They argue that in an organisational context, strategy and vision are distinct constructs. Time, however, is one of the areas of particular concern in relation to sustainability. Researchers exhaustively emphasise how the next thirty years are of utmost importance in determining what kind of world we and future generations will inhabit (Figueres \& Rivett-Carnac, 2020) and there is an increasing call to leverage policy making to realise a transition away from prevailing linear towards circular socio-economic practices (Boch et al., 2021; Prendeville et al., 2018; Savini, 2017). Sustainability requires long-term future orientation, which includes both anticipation of unintended consequences and envisioning desirable and sustainable futures (Gibson, 2006). As such, we believe that vision thinking should not be ignored in the context of sustainability and add it as a fourth activity to the list of three identified by Srivastava \& D'Souza (2021). Figure 1 outlines the qualities of each of the four activities. Later, we will explore how design-driven foresight can support strategic thinking across these activities.

\section{VISION THINKING}

Represents the ability to develop a sense of possible futures as to providera directio and a focus for strategic thinking activties ( $\operatorname{Bn} \quad n, 2005$ ). However, it is not the vision alone that is decisive, but the gap between today's reality and a more desirable future, which offers a directio for strategicsthinking activ tie (li edt k a, 1998; Srivastava \& D’Souza, 2021).

\section{DIVERGENT THOUGHT PROCESSING}

Reflects the ability to identify, use and think beyond existin c onceptio s, assumptio s and beliefs, so that ultim tely creative insights, understandings and solutio $\mathrm{s}$ for a given context can be developed (Heracleous, 1998; Lawrence, 1999; Pisapia et al., 2005; Srivastava \& D'Souza, 2021; Zahra \& Nambisan, 2012).

\begin{tabular}{l|l|}
\multicolumn{2}{|c|}{ REFLECTION } \\
$\begin{array}{l}\text { Represents the interactio of a persons' beliefs, } \mathrm{n} \\
\text { THINKING }\end{array}$ & $\begin{array}{l}\text { Refers to a holisticui e } w \text { that recognises the complete } \\
\text { system and its interdependencies across scales (Liedt- } \\
\text { ka, 1998). Hence, an individual must not only be able } \\
\text { person. It follows that reflentio does not just occur } \\
\text { in an individual's mind, but it is a recursive and ana- } \\
\text { lytical process that is influnced b y the social context } \\
\text { consideratio but also beyond (Srivastava \& D'Souza, } \\
\text { and which aims to use the generated knowledge to } \\
\text { draw conclusions (Pisapia et al., 2005; Srivastava \& } \\
\text { D'Souza, 2021). }\end{array}$ \\
\hline
\end{tabular}

Figure 1. Strategic thinking activities in relation to sustainability

\subsection{Design-driven foresight to support strategic thinking}

Over the last years, design and foresight grew closer together, and practitioners of both disciplines started to become interested in understanding how the respective other discipline can augment their own (Gordon et al., 2019; Hines \& Zindato, 2016). Within the design field, the interest in the future 
led to the emergence of various interrelated design/futures practices, such as speculative design, critical design, or design fiction. These practices emphasise design less as an outcome-oriented problem-solving approach, but more as an inquiry-oriented mindset that encourages critical thinking, critique, and debate around what is and what could be, often through the utilisation of designed artefacts (Auger, 2013).

In this paper, we see design first and foremost as a participatory process that attempts to approach problems through iterative, human-centered learning cycles of divergent and convergent modes of thinking, and which harnesses material-anchored tools and methods, such as visualisations (Brown, 2019). Foresight, we understand as "the ability, the skill and art of describing, explaining, exploring, predicting and/or interpreting future developments, as well as assessing their consequences for decisions and other actions in the present" (Berkhout, 2007, p. 74). In short, we understand foresight as a means geared towards exploring a changing landscape and design as a means geared towards influencing certain aspects of that landscape (Buehring \& Bishop, 2020).

The value of design-driven foresight for strategic thinking can be anchored to two major aspects. First, design has an experiential dimension (Wetter-Edman et al., 2018), which when applied to foresight, can lead to immersive simulations and tangible, sensory, and embodied experiences of the future (Buehring \& Liedtka, 2018; Candy \& Dunagan, 2017). These embodied experiences can ignite a process of re-perception in which people challenge their assumptions and advance collective visions, and by that means trigger strategic thinking and eventually change (Buehring \& Liedtka, 2018; Schwartz, 1996; Wetter-Edman et al., 2018). Second, design methods and tools are valued for their ability to support collaborative meaning making processes, for example, by translating knowledge into widely accessible formats that are equally understandable even to diverse stakeholders (Simeone et al., 2017).

Harnessing design-driven foresight to support strategic thinking has not been subject to much research yet and the few existing contributions focus solely on the business realm (e.g. Buehring \& Bishop, 2020; Buehring \& Liedtka, 2018). As such, we pose the following research question: How can design-driven foresight support strategic thinking in relation to sustainability and circular policy making?

\section{Research Methods}

This paper draws on two design experiments (Bang \& Eriksen, 2014) conducted in a class for the master's students of a programme in service design at a Danish University. Experiments play a core role in conducting research through design, in theory construction as well as in knowledge generation (e.g. Bang \& Eriksen, 2014). Such experiments are generally organized around two tracks: On the one hand, design is used to frame and address specific problems or issues of concern; on the other, this process is the occasion to reflect upon specific aspects of design (e.g., tools and methods, procedures, theoretical frameworks). The knowledge and the key learning points developed through these design experiments can, potentially, be employed elsewhere (Koskinen et al., 2013).

We carried out two half-a-day design experiments with the ultimate goal to explore how designdriven foresight can support the students' strategic thinking in relation to sustainability across the associated activities of vision thinking, divergent thought processing, reflection and systems thinking. The experiments took place virtually, using miro, an online whiteboard tool for visual collaboration. The participants were a semester group of 39 students, divided into eight groups. 
Figure 2 illustrates the ten-step process of the design experiments, which began with a theoretical introduction to foresight (1). After that, each group created a persona (e.g. Cooper, 2004; Nielsen, 2004) through whose eyes they would explore the future of Copenhagen in 2050 in the further course of the experiment (2). Next, the students explored, through desktop research, which drivers of change (e.g. Schwartz, 1996; Smith, 2020; van der Duin, 2016) will affect the world and the persona in the future (3). To further ignite the students' imagination around how these drivers of change may manifest, we employed a future visualization exercise (4). Thereupon, each group crafted a pessimistic and an optimistic scenario (e.g. Burnam-Fink, 2015; Lindgren and Bandhold, 2004; Madsen and Nielsen, 2010; Schwartz, 1996; van der Duin, 2016) for the persona living in Copenhagen in 2050 (figure 3 and 4) (5). The groups presented everything they had developed up to that point on the miro board, so that they could learn and get inspired from each other (6). In the next step, we introduced the students to the concept of a Circular Economy and Circular City as exemplary sustainability concepts (7), whereupon they iteratively revised their optimistic scenario considering aspects of circularity (8). Based on these activities, we asked the students to develop ideas for potential policy interventions (figure 5 ) to support the realisation of the optimistic circular scenario (e.g. Baumgartner and Korhonen, 2010; Liedtka, 1998; Srivastava and D'Souza, 2021) (9). Last, the groups presented their final outcomes on the miro board again (10).

We collected data through various methods. First, we observed the students' activities on the miro board during the experiments (Muratovski, 2016) and examined their exhibited outcomes. Following the design experiments, each group answered a questionnaire (Trochim et al., 2016). Here, we employed a group-administered questionnaire to enable the students to have more granular reflections through discussing the questions and individual ideas as a group before responding (ibid.). Additionally, ten students participated in semi-structured interviews, where the interviewer asked follow-up and more open-ended questions that triggered even deeper considerations and reflections in the students (Muratovski, 2016; Trochim et al., 2016). We iteratively analysed the data that we retrieved from various sources to reduce single-observation biases (Tarrow, 1995).

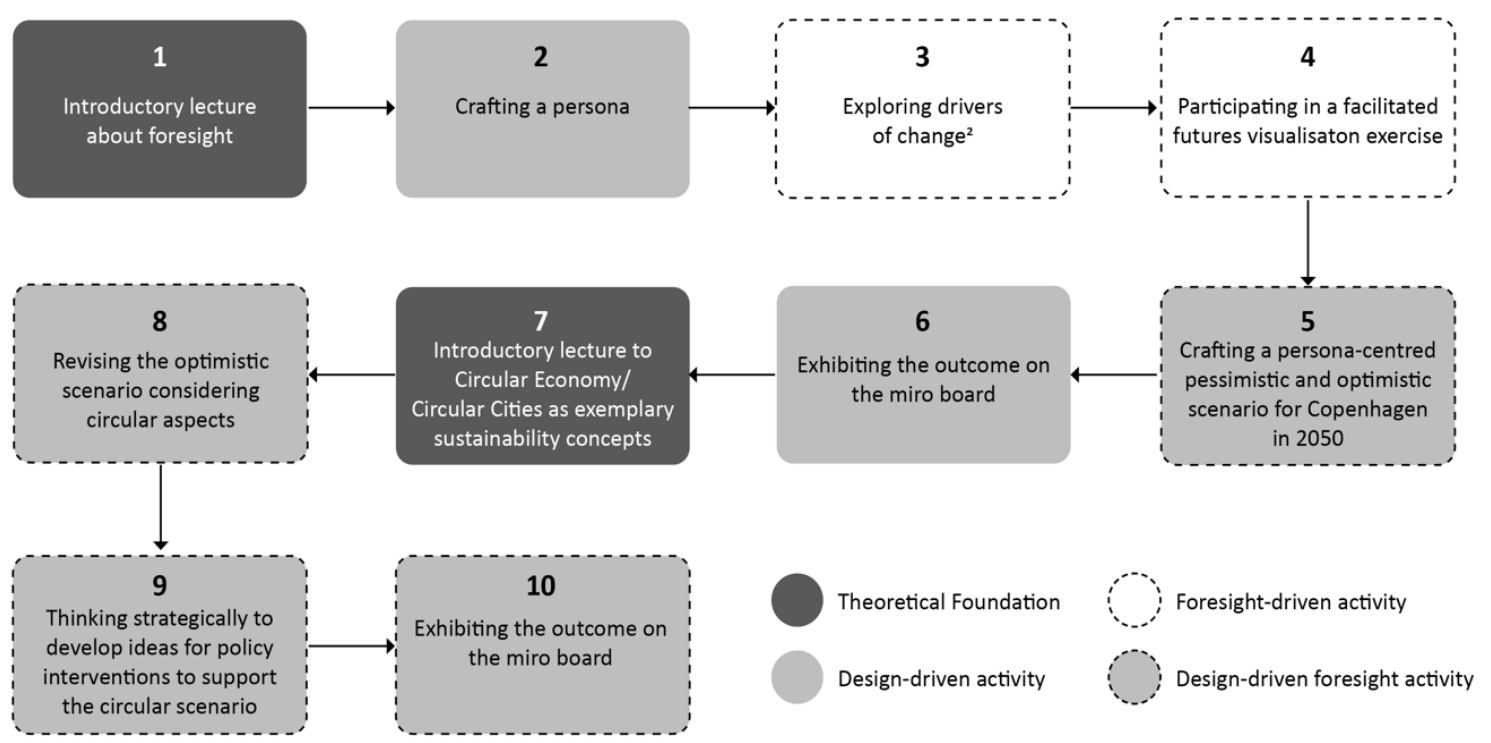

Figure 2. Overview of design-driven foresight process employed in design experiments 


\section{Findings}

When examining the students' scenarios, it became apparent that they, through the help of design methods, created vivid representations of potential futures and their shared fears and hopes in relation to them (figures 3 and 4). For example, various groups employed persona-centred journey maps and illustrated them with images, photos or scribbles, and vivid language ("she checks the pollution forecast to decide which kind of protective gear her family will have to wear today. The data are really alarming so she chooses a hazmat suit. To make sure that the children have a safe trip to school, the parents give them to a paramilitary organisation responsible to walk them to school")

(figure 3). By articulating the scenarios from a persona's point of view, light was shed on very specific problems but also opportunities, in the everyday reality of city dwellers in relation to sustainability. This formed a fruitful basis for the identification of appropriate points for policy interventions, which can potentially leverage the transition towards the circular scenario. For example, one group identified the dependency on drones for food supply and the potential disruption of those supply chains as a possible future problem (figure 3 ). In their circular scenario they articulated a future in which nutritious-optimised food is grown in home cultivation (figure 4). As a policy intervention they suggest that each newly built house needs to have at least $10 \%$ of its square meters dedicated to growing produce (figure 5). This strategic thinking process is very much in line with Rumelt's (2011) description of good strategic work, which, according to him, involves designing a set of coherent actions that are carried out to overcome obstacles identified in a diagnosis.

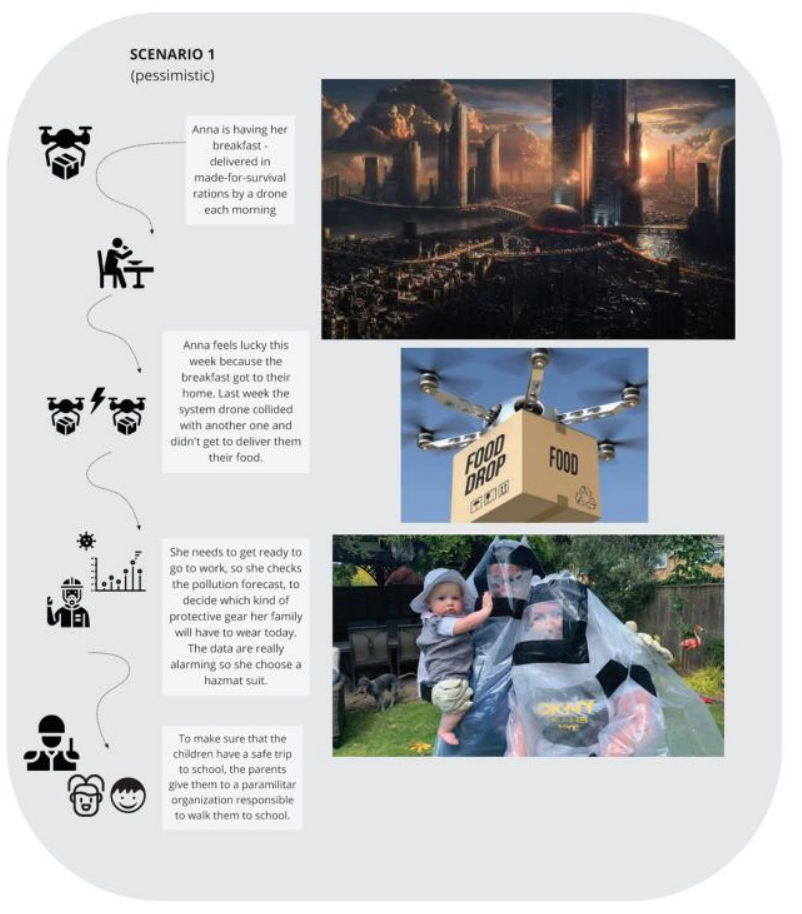

Figure 3. Pessimistic scenario

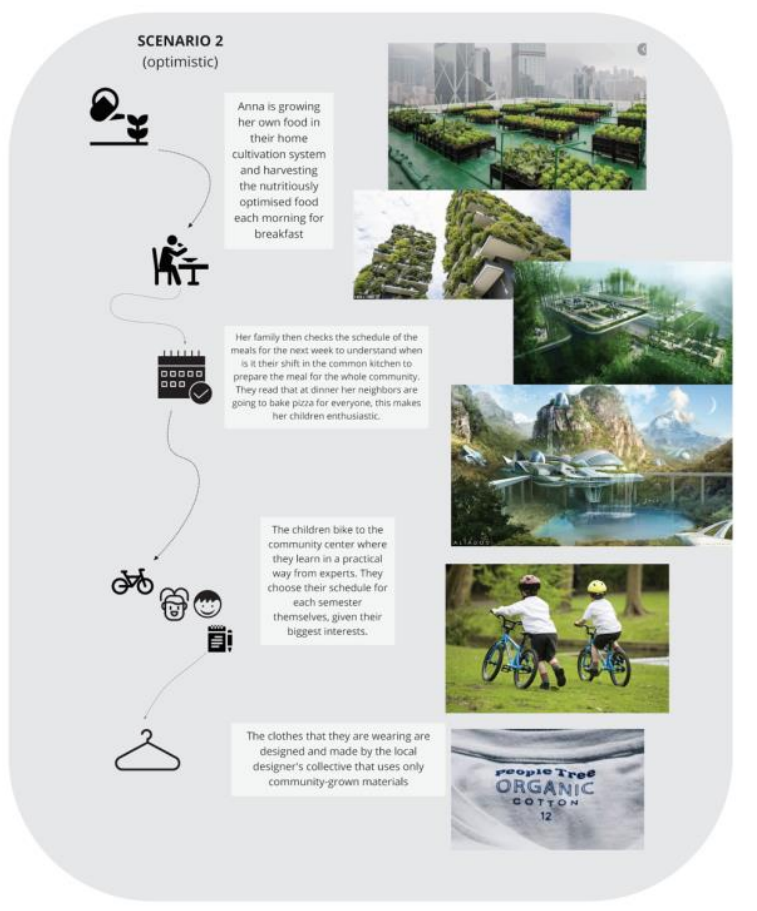

Figure 4. Optimistic scenario 


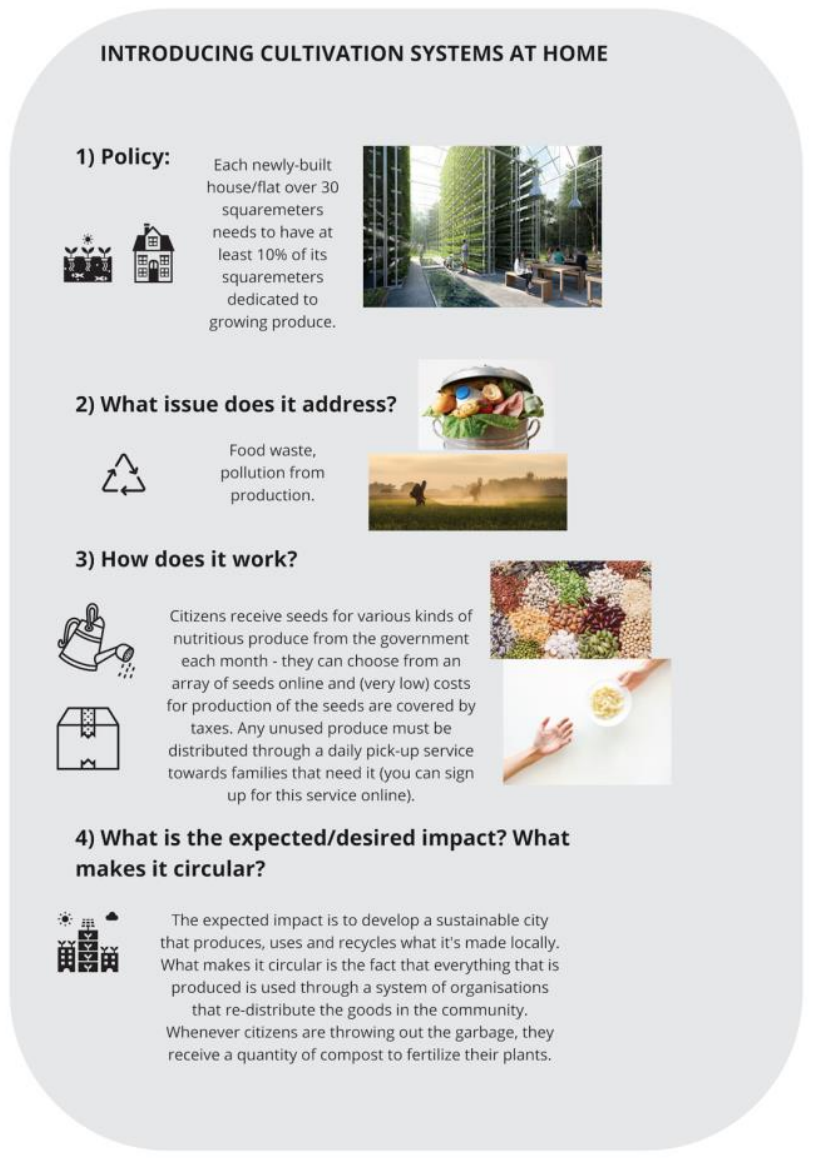

Figure 5. Policy interventions

During the interviews a student reflected on how today's pop culture tends to produce dystopian future visions ("there has never been a movie about 2050 where we solved the climate crisis"), and how these visions lead to negative assumptions about what is ahead of us. The students suggested that the design-driven foresight approach "made room for imagination", and "enhanced creativity and awareness" that the commonly told stories are not the only way the future can unfold (e.g. "I had a voice creeping in, saying that humans won't even be able to walk outside and breathe anymore, like a total dystopia. I'm usually a very pessimistic and careful person." She goes on and describes how the process made her go in another direction for once and how then "all these images of self-sustainability and smaller communities and solidarity came up".) According to the students, through design the imagined futures became "vivid", "engaging", and "immersive" representations of more sustainable and liveable futures, which challenged those dominant assumptions and released a motivating force to take action to alter the status quo so that ultimately more sustainable futures will become reality.

Our study also revealed how design methods can facilitate these somehow emotional, and complex socio-political processes in which desirable future change is negotiated and co-created. For example, the persona appeared to serve as a means to accommodate diverse views in relation to the future ("It's easier to address conflicting opinions about the future or the elephant in the room, because it's not about any of us, but it's about this persona") and provided a safe space to explore the future ("It's psychologically way easier to picture the persona's life than to picture my own future. It's an option to face future challenges but without the weight of your own experiences, trauma and challenges on your shoulders"). Furthermore, the translation and communication mechanisms of design were highlighted as helpful means to identify common ground: "I remember that we started 
explaining to each of us what we saw during the time travel. But it's difficult sometimes to explain what you have in your mind. So then we started to do so with pictures, and then some of us were like 'oh this is also how I picture it!'”. Becoming aware of the future's pluralistic nature as exemplified by the diverse visions of peers, lead to "accept other visions that you might not have yourself".

The students reflected on how they alternated between exploration and synthesis ("I feel like the trend exploration was very exploratory and inspirational", "the persona helped us to align and provided a focus, like a lens through which to explore the future"). Furthermore, they described how they iteratively refined the scenario and thereby gradually developed a shared vision of a preferable future.

It was voiced how the negative scenario helped to make an informed choice regarding what to prevent, whilst sensing a preferable scenario gave a vision to strive for, one that motivates to "create the future, rather than letting it be created". Statements like "we got an idea about how cities in the future could feel like and that gave us insights that we can use to design in the present", or "it connected us to the future through the channel of visuals" suggest that design-driven foresight can potentially help to bridge the gap between the present and the future. Being asked whether they see value in the approach, one student expressed: "Absolutely! You can only create what you can envision!"

\section{Discussion}

In the following, we discuss how design-driven foresight supported strategic thinking in relation to the four associated activities, which however cannot be put into boxes but are interrelated with blurred boundaries.

\subsection{Vision thinking}

Our study resonated with previous research (Buehring, 2017) by indicating that design and foresight are powerful collaboration partners to support vision thinking. While foresight created awareness around the multiplicity of possible futures and their openness to be defined by actions in the present, design complemented foresight by crafting immersive and engaging representations of those various futures that may lie ahead, which enabled people to experience, to feel, how it may be like to live in those futures. This experience combined with the ability to discuss, refer and relate to fine-grained, materially-anchored future representations allowed for more granular and coordinated conversations and negotiations about what is and is not desirable with a view on more sustainable futures. Design also allowed for the identification of the lowest common denominator of the group members participating in the design-driven foresight process. For example, when visions were communicated in images, similar images could be clustered to gain insights into the extent to which individual visions overlapped or differed. This approach supported the creation of shared visions, which in turn, laid a foundation to derive a set of coordinated circular policy interventions that could realise the transition towards that shared sustainable vision.

\subsection{Divergent thought processing}

Like a compass to explore uncharted territory, design-driven foresight emerged as a navigational approach into the plurality and uncertainty of futures, in which the material dimension of co-creating diagrams and visual stories provided an anchor for uncovering, managing, and harnessing possible change, shared and conflicting hopes and fears, and collective assumptions. Design-driven foresight 
was, however, not only tied to divergent thinking but ignited an alternation between divergent and convergent modes of thinking and doing, in which the materiality of design augmented foresight by synthesising, capturing, and reducing the often somewhat overwhelming density of mere speech.

\subsection{Reflection}

Design-driven foresight enabled a coordinated, productive and reflective discussion, and an evaluation of the pros and cons of the status quo and of possible futures. Design facilitated this sometimes tense negotiation practice, in which partly different worldviews and visions collided, by translating what was being said in physical representations, which the discussions and negotiations could be based upon. Our findings complement previous research (Simeone et al., 2018) by indicating that these translational and communicational mechanisms of design not only sooth tensions but support collective meaning making processes by allowing nuanced representations of complex issues or individual ideas that can hardly be expressed in words. While language was sometimes misleading, visuals had an immediate and direct effect, were easier to grasp and process, and conveyed emotional content. As such, design built a bridge between the individuals' strategic thinking activities and their application to the social context, in which a collective aimed to derive meaning and to imagine and design circular policy interventions towards sustainability.

\subsection{Systems thinking}

Our study pointed at how design-driven foresight can support systems thinking through its ability to foster a collective learning process, which uncovers, challenges and reframes anticipatory assumptions that determine what people see and do in the present (Miller et al., 2018). This powerful process was greatly leveraged by design. As design methods facilitated the inclusion of and translation between diverse perspectives, the conditions for productive dissent, dialogue and reperception were created. Furthermore, design made hidden assumptions, which were embedded in the students' visions and ideas about the future, literally visible and thus enabled the identification of mental 'boxes'. Awareness around individual and collective assumptions forms the basis not only for seeing the reality as it actually is, opposed to how you assume it to be (Schwartz, 1996), but also for assessing whether one is thinking and moving outside of these boxes (Miller et al., 2018). Ultimately, awareness over assumptions is what is a cornerstone for being able to realise desirable change, i.e. for taking deliberate and coordinated policy actions that support a transition towards more desirable and circular future states.

\section{Conclusion}

This paper has brought forth various indications about how design-driven foresight can support strategic thinking in relation to sustainability and circular policy making. On the one hand, it could be seen as a limitation that this approach was tested with students in academia and we acknowledge the fact that real world policy making deals with a level of complexity that goes beyond this classroom setting. On the other hand, we see a great potential in engaging students as knowledgeable citizens with valuable ideas, emphasising their agency, stewardship, and the importance of their contribution for sustainability and circular policy making. As future decisionmakers, but also in their role as voters, they make a significant contribution to the transition of socioecological systems into futures that embrace and foster circularity. We acknowledge that it is beyond the scope of this paper to discuss all indications in-depth and that each indication may call for more 
studies. As such, we would like the readers to consider this paper as an appetiser and invitation to further research.

\section{References}

Auger, J. (2013). Speculative Design: Crafting the Speculation. Digital Creativity, 24(1), 11-35. https://doi.org/10.1080/14626268.2013.767276

Balkenende, R., Bocken, N., \& Bakker, C. (2017). Design for the Circular Economy. In Routledge Handbook of Sustainable Design (pp. 498-513). Routledge. http://lup.lub.lu.se/record/d128176ccbef-4f49-9b53-b166de56abda

Burnam-Fink, M. (2015). Creating narrative scenarios: Science fiction prototyping at Emerge. Futures, 70, 48-55. https://doi.org/10.1016/j.futures.2014.12.005

Bang, A. L., \& Eriksen, M. A. (2014). Experiments all the way-Diagrams of dialectics between a design research program and experiments. Artifact, 3(2), 4.

https://doi.org/10.14434/artifact.v3i2.3976

Baumgartner, R., \& Korhonen, J. (2010). Strategic Thinking for Sustainable Development. Sustainable Development, 18, 71-75. https://doi.org/10.1002/sd.452

Berkhout, G. (2007). The cyclic nature of innovation: Connecting hard sciences with soft values. Elsevier Jai.

Boch, R., Gallen, J., \& Hempel, N. (2021). Paths Towards A Circular Society: The Potential of Social Design for Social Transformation. Social Design Lab, Hans Sauer Stiftung.

Bofylatos, S., Spyrou, T., Darzentas, J. S., \& Darzentas, J. (2012). Designing for Sustainability: A generic Framework. Crafting the Future, 11.

Bonn, I. (2005). Improving strategic thinking: A multilevel approach. Leadership \& Organization Development Journal, 26(5), 336-354. https://doi.org/10.1108/01437730510607844

Buehring, J., \& Liedtka, J. (2018). Embracing systematic futures thinking at the intersection of Strategic Planning, Foresight and Design. 19.

Buehring, J., \& Bishop, P. C. (2020). Foresight and Design: New Support for Strategic Decision Making. She Ji: The Journal of Design, Economics, and Innovation, 6(3), 408-432.

https://doi.org/10.1016/j.sheji.2020.07.002

Buehring, J., \& Liedtka, J. (2018). Embracing systematic futures thinking at the intersection of Strategic Planning, Foresight and Design. 19.

Candy, S., \& Dunagan, J. (2017). Designing an experiential scenario: The People Who Vanished. Futures, 86, 136-153. https://doi.org/10.1016/j.futures.2016.05.006

Candy, S., \& Kornet, K. (2019). Turning Foresight Inside Out: An Introduction to Ethnographic Experiential Futures. Journal of Futures Studies, 23, 3-22. https://doi.org/10.6531/JFS.201903_23(3).0002

Casey, A., \& Goldman, E. (2010). Enhancing the ability to think strategically: A learning model. Management Learning - MANAGE LEARNING, 41, 167-185. https://doi.org/10.1177/1350507609355497

Cooper, A. (2004). The Inmates Are Running the Asylum: Why High Tech Products Drive Us Crazy and How to Restore the Sanity (2nd ed.). Sams Publishing. 
Destatte, P. (2010). Foresight: A major tool in tackling sustainable development. Technological Forecasting and Social Change, 77(9), 1575-1587. https://doi.org/10.1016/j.techfore.2010.07.005

Evans, M. (2010). Design Futures: An Investigation into the Role of Futures Thinking in Design. Lancaster Institute for the Contemporary Arts, Lancaster University.

Figueres, C., \& Rivett-Carnac, T. (2020). The Future We Choose: Surviving the Climate Crisis (Illustrated Edition). Knopf.

Gibson, R. B. (2006). Sustainability assessment: Basic components of a practical approach. Impact Assessment and Project Appraisal, 24(3), 170-182. https://doi.org/10.3152/147154606781765147

Giraldo Nohra, C., Pereno, A., \& Barbero, S. (2020). Systemic Design for Policy-Making: Towards the Next Circular Regions. Sustainability, 12, 4494. https://doi.org/10.3390/su12114494

Goldman, E., Scott, A., \& Follman, J. (2015). Organizational practices to develop strategic thinking. Journal of Strategy and Management, 8(2). https://doi.org/10.1108/JSMA-01-2015-0003

Gordon, A., Rohrbeck, R., \& Schwarz, J. (2019). Escaping the "Faster Horse" Trap: Bridging Strategic Foresight and Design-Based Innovation. Technology Innovation Management Review, 9(8).

Graetz, F. (2002). Strategic thinking versus strategic planning: Towards understanding the complementarities. Management Decision, 40(5), 456-462.

https://doi.org/10.1108/00251740210430434

Grunwald, A. (2004). Strategic knowledge for sustainable development: The need for reflexivity and learning at the interface between science and society. International Journal of Foresight and Innovation Policy, 1(1-2), 150-167. https://doi.org/10.1504/IJFIP.2004.004619

Hale, A., Archambault, L., \& Foley, R. (2015). Sustainability Education Framework for Teachers: Developing sustainability literacy through futures, values, systems, and strategic thinking. The Journal of Sustainability Education, 6.

Heracleous, L. (1998). Strategic Thinking or Strategic Planning? Long Range Planning, 31(3), 481-487.

Héry, M., \& Malenfer, M. (2020). Development of a circular economy and evolution of working conditions and occupational risks - A strategic foresight study. European Journal of Futures Research, 8(1), 8. https://doi.org/10.1186/s40309-020-00168-7

Hines, A., \& Zindato, D. (2016). Designing Foresight and Foresighting Design: Opportunities for Learning and Collaboration via Scenarios. World Futures Review, 8(4), 180-192. https://doi.org/10.1177/1946756716672477

Isaacs, W. (1999). Dialogue: The Art Of Thinking Together (Illustrated Edition). Currency.

Koskinen, I., Zimmerman, J., Binder, T., Redstrom, J., \& Wensveen, S. (2013). Design Research Through Practice: From the Lab, Field, and Showroom. IEEE Transactions on Professional Communication, 56(3), 262-263. https://doi.org/10.1109/TPC.2013.2274109

Lewis, H., Gertsakis, J., Grant, T., \& Andrew, S. (2017). Design + Environment: A Global Guide to Designing Greener Goods. Routledge.

Liedtka, J. M. (1998). Strategic thinking: Can it be taught? Long Range Planning, 31(1), 120-129. https://doi.org/10.1016/S0024-6301(97)00098-8

Lindgren, M., \& Bandhold, H. (2004). Scenario planning: The link between future and strategy (4. [pr.]). Palgrave.

Nielsen, L. (2004). Engaging Personas and Narrative Scenarios. Copenhagen Business School.

Madsen, S., \& Nielsen, L. (2010). Exploring Persona-Scenarios-Using Storytelling to Create Design Ideas. In D. Katre, R. Orngreen, P. Yammiyavar, \& T. Clemmensen (Eds.), Human Work Interaction 
Design: Usability in Social, Cultural and Organizational Contexts (pp. 57-66). Springer Berlin Heidelberg.

Miller, R., Poli, R., Rossel, P., Tuomi, I., Ehresmann, A., Béjean, M., Vanbremeersch, J.-P., Kamara, K., Aceron, A. V., Akomolafe, B., Arellano, A., Bergheim, S., Cagnin, C., Candy, S., Cedeño, O., Leroy, S., Cruz, S., Djidingar, N., Eyakuze, A., \& Simard, N. (2018). Transforming the Future: Anticipation in the 21st Century. In Transforming the Future: Anticipation in the 21st Century. https://doi.org/10.4324/9781351048002

Mintzberg, H. (1994). The Fall and Rise of Strategic Planning. 11.

Muratovski, G. (2016). Research for Designers: A Guide to Methods and Practice. SAGE Publications Ltd. https://us.sagepub.com/en-us/nam/book/research-designers

Prendeville, S., Cherim, E., \& Bocken, N. (2018). Circular Cities: Mapping Six Cities in Transition. Environmental Innovation and Societal Transitions, 26, 171-194. https://doi.org/10.1016/j.eist.2017.03.002

Rumelt, R. (2011). Good Strategy/Bad Strategy. Profile Books. https://www.thalia.de/shop/home/artikeldetails/ID57340445.html?ProvID=11000522\&ProvID=11 019522\&gclid=CjwKCAiA65iBBhBEiwAW253W8IwCrQ1jo1mXsBbADf6UwBXvsIvyAFSrZ8zy4pYmiovSoJkQbFfhxoCv-oQAvD_BwE

Savini, F. (2017). Wasted Experiments: A Commentary on Amsterdam Policy for a Circular Society. In The Watsed City: Approaches to Circular City Making (pp. 131-134). Valiz Trancity.

Schwartz, P. (1996). Art of the Long View: Planning for the Future in an Uncertain World. Currency. https://www.wiley.com/engb/Art+of+the+Long+View\%3A+Planning+for+the+Future+in+an+Uncertain+World-p9780471977858

Simeone, L. (2020). Characterizing Strategic Design Processes in Relation to Definitions of Strategy from Military, Business and Management Studies. The Design Journal, 23(4), 515-534. https://doi.org/10.1080/14606925.2020.1758472

Simeone, L., Secundo, G., \& Schiuma, G. (2017). Knowledge translation mechanisms in open innovation: The role of design in R \& D projects. Journal of Knowledge Management, 21, 14061429. https://doi.org/10.1108/JKM-10-2016-0432

Simeone, L., Secundo, G., \& Schiuma, G. (2018). Arts and design as translational mechanisms for academic entrepreneurship: The metaLAB at Harvard case study. Journal of Business Research, 85, 434-443. https://doi.org/10.1016/j.jbusres.2017.10.021

Smith, S. (2020). How To Future. Kogan Page Inspire.

Srivastava, S., \& D'Souza, D. (2021). Measuring Strategic Thinking in Organizations. Journal of Managerial Issues, XXXIII(1), 90-111.

Tarrow, S. (1995). Bridging the Quantitative-Qualitative Divide in Political Science. American Political Science Review, 89(2), 471-474. https://doi.org/10.2307/2082444

Trochim, W. M., Donnelly, J. P., \& Arora, K. (2016). Research Methods: The Essential Knowledge Base (2nd ed.). Cengage Learning.

van der Duin, P. (2016). Foresight in Organizations: Methods and Tools. Routledge.

Warren, A. E., Archambault, L. M., \& Foley, R. W. (2014). Sustainability Education Framework for Teachers: Developing sustainability literacy through futures, values, systems, and strategic thinking. 6, 14. 
Wetter-Edman, K., Vink, J., \& Blomkvist, J. (2018). Staging aesthetic disruption through design methods for service innovation. Design Studies, 55, 5-26.

https://doi.org/10.1016/j.destud.2017.11.007

Wiek, A., Withycombe, L., \& Redman, C. L. (2011). Key competencies in sustainability: A reference framework for academic program development. Sustainability Science, 6(2), 203-218.

https://doi.org/10.1007/s11625-011-0132-6

Wiener, M., Gattringer, R., \& Strehl, F. (2020). Collaborative open foresight-A new approach for inspiring discontinuous and sustainability-oriented innovations. Technological Forecasting and Social Change, 155, 119370. https://doi.org/10.1016/j.techfore.2018.07.008

Author Bios:

Rike Neuhoff is a PhD student at Aalborg University with a background in Service Systems Design. Her research explores how participatory design approaches can be combined with futuring approaches to support a participatory transformation towards Circular Cities.

Luca Simeone is Associate Professor at Aalborg University (Denmark) and has conducted research and teaching activities in various universities (Harvard, MIT, Milan Polytechnic, Malmö University, University of the Arts London), mostly exploring the managerial, strategic and organizational aspects of design.

Lea Holst Laursen is an Associate Professor at Aalborg University. Her research concerns urban and rural transformation with a place-based, human-centred objective - inquiring and discussing urban and rural futures through user involvement and urban design methods. 